\section{Adult with exertional dyspnoea and abnormal ECG}

\section{CLINICAL INTRODUCTION}

A man in his 60 s with hypertension and tobacco use presented to the outpatient clinic with 3 -month progressive exertional dyspnoea. ECG showed sinus rhythm with poor R-wave progression in the precordial leads. Transthoracic echocardiography (TTE) revealed normal left ventricular (LV) size and function. Coronary angiography showed no significant stenosis. However, left ventriculography found a narrow neck, thin-walled outpouching at the apex with synchronous contraction (figure $1 \mathrm{~A}, \mathrm{~B}$ and video 1). Subsequently, MRI confirmed a small LV outpouching on the apex measuring $17 \times 12 \mathrm{~mm}$, which contained myocardium (figure $1 \mathrm{C}, \mathrm{D}$ and video 2). On late gadolinium enhancement images, the entire LV myocardium was nulled without evidence of scar. During the period of follow-up, the size and location of his LV outpouching remained unchanged over time.

\section{QUESTION}

What is the most probable diagnosis of this patient?
A. LV pseudoaneurysm.
B. LV aneurysm.
C. LV diverticulum.
D. Apical ballooning syndrome.
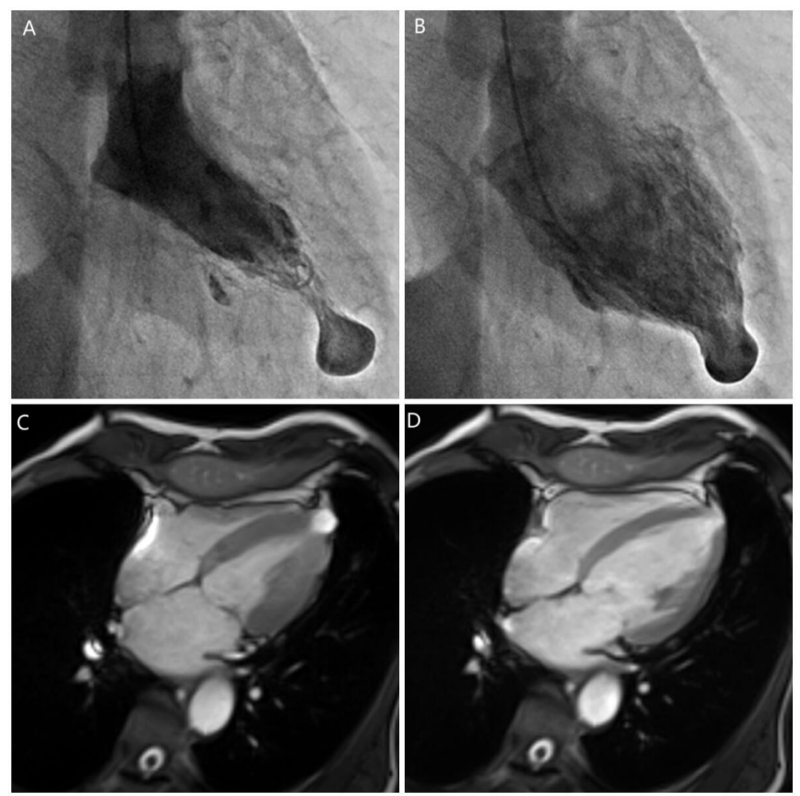

Figure 1 Ventriculogram (right anterior oblique projection) showing the contrast-filled outpouching at the apex during systole (A) and diastole (B). MRI (long axial plane of the left ventricular view) showing a small outpouching on the apex during systole (C) and diastole (D).

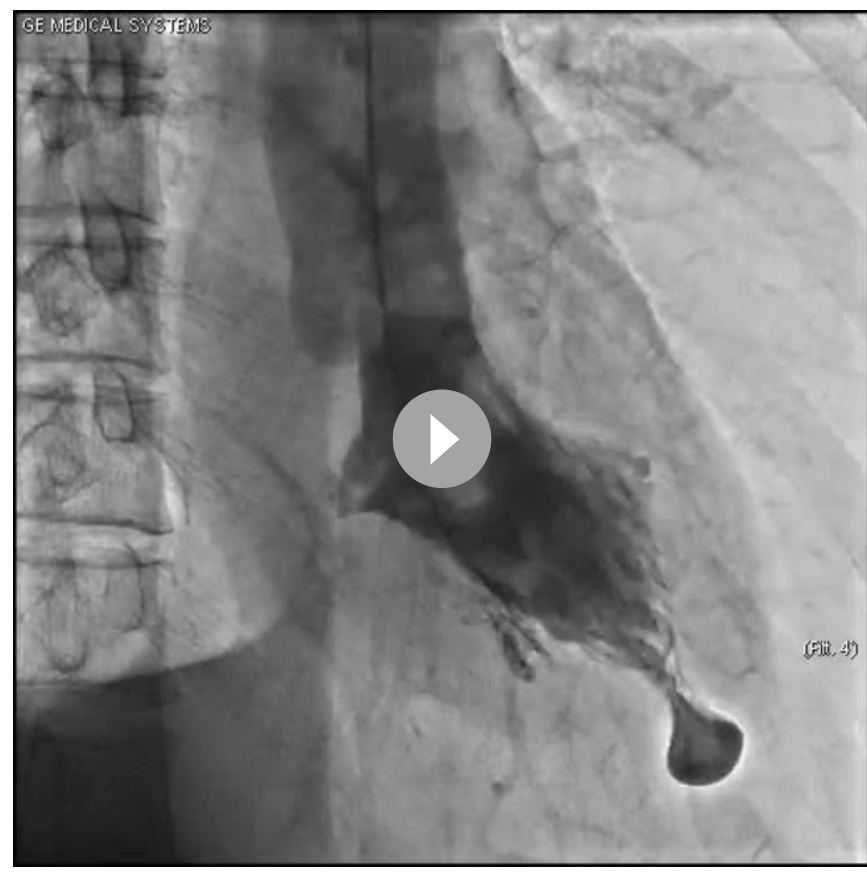

Video 1 Left ventriculogram in right anterior oblique projection showing a narrow neck, thin-walled outpouching at the apex with mild contraction synchrony.

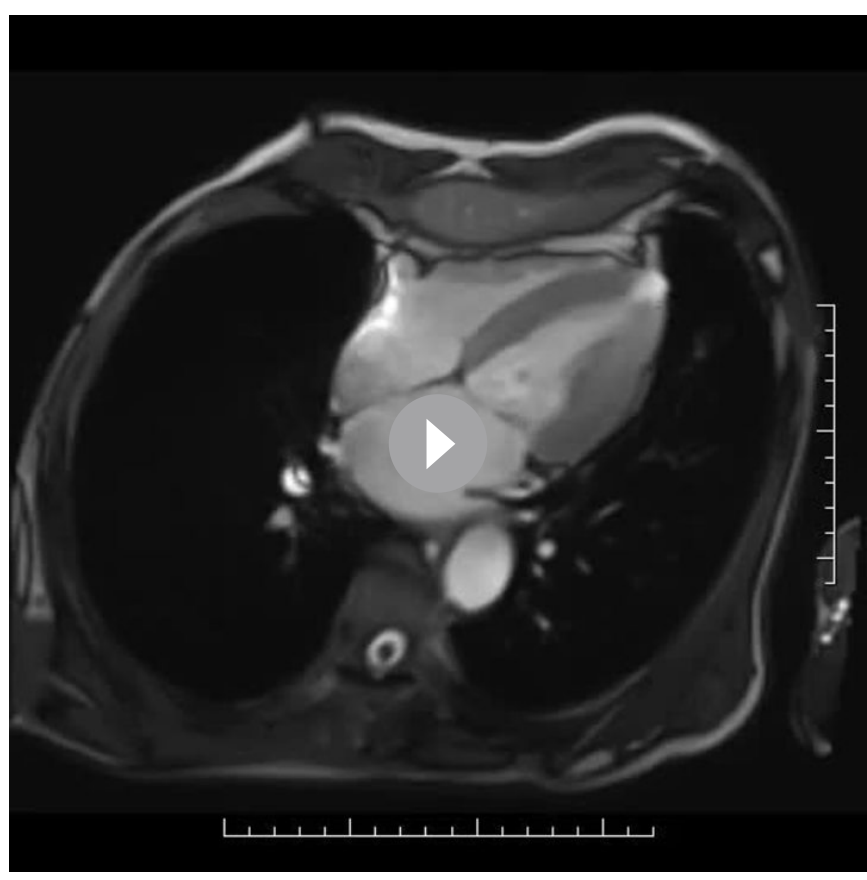

Video 2 MRI (long axial plane of the left ventricular view) showing a small outpouching on the apex.

For answer see page 1102 


\section{Adult with exertional dyspnoea and abnormal ECG}

For question see page 1039

\begin{abstract}
ANSWER: C
LV diverticulum is defined by a narrow-necked saccular outpouching that extends beyond the confines of the myocardium and contracts with the ventricle, as is seen in this case. Aneurysms are nearly always associated with total occlusion of the coronary artery, usually the left anterior descending. Pseudoaneurysm is a false aneurysm, resulting from a contained rupture of the LV wall, a rare complication following myocardial infarction (MI). Apical ballooning syndrome is a usually reversible cardiomyopathy that may be precipitated by stress or critical illness and can mimic MI. In our case, coronary angiography demonstrated normal coronary arteries and MRI found no signs of MI, making aneurysm and pseudoaneurysm unlikely.

Two types of diverticulum have been reported: muscular and fibrous types. ${ }^{12}$ The fibrous type is located at the ventricular apex or a subvalvular position, without distinct contraction. It is not associated with other congenital cardiac malformations, and thus may be diagnosed only in adulthood. The diverticulum in our patient was consistent with the fibrous type of congenital LV diverticulum. In adult presentation, diverticula are discovered incidentally during cross-sectional diagnostic imaging procedures, such as echocardiography, cardiac MRI or cardiac catheterisation. ${ }^{3}$ Diverticula can be difficult to diagnosis by TTE, but contrast echocardiography can be useful. Management of ventricular diverticula remains uncertain and treatment options include either observation and surgery. ${ }^{4}$ If the diverticulum is small and asymptomatic, as in our case, a conservative treatment with follow-up is often recommended.
\end{abstract}

\section{Li Zhou $\odot$, Hui Chen, Hongwei Li $\odot$}

Department of Cardiology, Cardiovascular Center, Capital Medical University Affiliated Beijing Friendship Hospital, Beijing, China

Correspondence to Professor Hui Chen, Department of Cardiology, Cardiovascular Center, Capital Medical University Affiliated Beijing Friendship Hospital, Beijing 100050, China; 13910710028@163.com
Contributors All authors gave the final approval of the version published. LZ wrote the first draft of the manuscript. LZ and HC were involved in the care of the patient. $\mathrm{HL}$ made revisions to the manuscript.

Funding $L Z$ is funded by the Beijing Municipal Administration of Hospitals Incubating Program (code PX2020006).

Competing interests None declared.

Patient and public involvement Patients and/or the public were not involved in the design, or conduct, or reporting, or dissemination plans of this research.

Patient consent for publication Not required.

Ethics approval The case report was approved by Beijing Friendship Hospital's committee on human research (approval number 2020-P2-138-01).

Provenance and peer review Not commissioned; internally peer reviewed.

\section{(2) \\ OPEN ACCESS}

Open access This is an open access article distributed in accordance with the Creative Commons Attribution Non Commercial (CC BY-NC 4.0) license, which permits others to distribute, remix, adapt, build upon this work non-commercially, and license their derivative works on different terms, provided the original work is properly cited, appropriate credit is given, any changes made indicated, and the use is non-commercial. See: http://creativecommons.org/licenses/by-nc/4.0/.

(c) Author(s) (or their employer(s)) 2021. Re-use permitted under CC BY-NC. No commercial re-use. See rights and permissions. Published by BMJ.

Check for updates

To cite Zhou L, Chen H, Li H. Heart 2021;107:1102.

Heart 2021;107:1102. doi:10.1136/heartjnl-2021-319230

ORCID iDs

Li Zhou http://orcid.org/0000-0002-2372-6758

Hongwei Li http://orcid.org/0000-0001-5900-7088

\section{REFERENCES}

1 Chesler E, Tucker RB, Barlow JB. Subvalvular and apical left ventricular aneurysms in the Bantu as a source of systemic emboli. Circulation 1967;35:1156-62.

2 Ohlow M-A, von Korn H, Lauer B. Characteristics and outcome of congenital left ventricular aneurysm and diverticulum: analysis of 809 cases published since 1816. Int J Cardiol 2015; 185:34-45.

3 Ohlow M-A. Congenital left ventricular aneurysms and diverticula: an entity in search of an identity. J Geriatr Cardiol 2017;14:750-62.

4 Cresti A, Franci L, Picotti A. Huge left ventricular diverticulum simulating athlete's heart, a multimodality imaging study. Heart 2013;99:1467-8. 